\title{
Colonizações radiculares por fungos micorrízicos arbusculares (FMAs) em áreas degradadas pela exploração petrolífera no Estado do Amazonas, Brasil
}

A recuperação de áreas degradadas na Amazônia é um desafio a ser enfrentado para que a região não sofra tanto impacto das ações antrópicas. As áreas degradadas de clareiras e jazidas causadas pela exploração petrolífera em Urucu servem de referencial para o desenvolvimento de tecnologias de recuperação em toda a Amazônia. O objetivo desse estudo foi avaliar a importância dos fungos micorrízicos arbusculares (FMAs) nos componentes dos solos que sofrem impactos direto e indireto da exploração petrolífera, a partir da análise nos níveis de colonização radicular de mudas de espécies florestais e frutíferas utilizadas na recuperação das áreas exploradas pela atividade petrolífera, assim como suas características simbióticas. Todos os solos mostraram-se ácidos e com teores elevados de Alumínio, com a maioria indicando a aplicação de adubação, principalmente com $\mathrm{Ca}, \mathrm{Mg}, \mathrm{K}, \mathrm{P}$ e Fe. Os baixos índices de hifas fúngicas encontrados nas raízes das plantas usadas na restauração ambiental das clareiras e jazidas sugerem que a simbiose com os fungos pouco ou nada contribuem para a nutrição das plantas naquelas condições edafoclimáticas.

Palavras-chave: Áreas degradadas; Restauração ambiental; Recuperação ambiental; Fertilidade dos solos; Espécies florestais da Amazônia.

\section{Root colonization's by arbuscular mycorrhizal fungi (FMAs) in areas degraded by oil exploration in the Amazonas State, Brazil}

\begin{abstract}
The recovery of degraded areas in the Amazon is a challenge to be faced so that the region does not suffer as much impact from human actions. The degraded areas on clearings and deposits caused by oil exploration in Urucu serve as a reference for the development of recovery technologies throughout the Amazon. The objective of this study was to evaluate the importance of arbuscular mycorrhizal fungi (FMAs) in soil components that suffer direct and indirect impacts from oil exploration, from the analysis of the levels of root colonization of seedlings of forest and fruit species used in the recovery of areas exploited by the oil activity, as well as its symbiotic characteristics. All soils proved to be acidic and with high levels of aluminum, with the majority indicating the application of fertilization, mainly with $\mathrm{Ca}, \mathrm{Mg}, \mathrm{K}, \mathrm{P}$ and $\mathrm{Fe}$. The low levels of fungal hyphae found in the roots of plants used in the environmental restoration areas suggest that symbiosis with fungi contribute little or nothing to the nutrition of plants in those edaphoclimatic conditions.
\end{abstract}

Keywords: Degraded areas; Environmental restoration; Environmental recovery; Soil fertility; Forest species in the Amazon.

Topic: Ciências do Solo

Reviewed anonymously in the process of blind peer.
Received: 02/02/2021 Approved: $25 / 02 / 2021$
Gisele Silva de Medeiros

Instituto Nacional de Pesquisas da Amazônia, Brasil http://lattes.cnpq.br/5337233106185883

http://orcid.org/0000-0002-8705-0558

gisele.medeiros@icmbio.gov.br

Francisco Wesen Moreira (iD)

Instituto Nacional de Pesquisas da Amazônia, Brasil http://lattes.cnpq.br/1416538021119110

http://orcid.org/0000-0002-8763-254X

wesen@inpa.gov.br

Luiz Antonio de Oliveira (id

Instituto Nacional de Pesquisas da Amazônia, Brasil

http://lattes.cnpq.br/9931395111001102

http://orcid.org/0000-0002-2008-7292

luiz.oliveira@inpa.gov.br
Referencing this:

MEDEIROS, G. S.; MOREIRA, F. W.; OLIVEIRA, L. A.. Colonizações radiculares por fungos micorrízicos arbusculares (FMAs) em áreas degradadas pela exploração petrolífera no Estado do Amazonas, Brasil. Revista Ibero Americana de Ciências Ambientais, v.12, n.2, p.27-34, 2021. DOI: http://doi.org/10.6008/CBPC21796858.2021.002.0004 


\section{INTRODUÇÃO}

A recuperação de áreas degradadas na Amazônia é um dos principais problemas causados pela ocupação antrópica na região. Para que as áreas já desmatadas possam contribuir para o desenvolvimento sustentável, é necessário que sejam usadas espécies de plantas capazes de se desenvolverem nesses solos pobres e por vezes degradados. Os solos das clareiras da base petrolífera de Urucu servem de referencial para o desenvolvimento de novas tecnologias na recuperação de áreas degradadas e entender a relação entre as plantas usadas nessas clareiras e os fungos micorrízicos arbusculares pode contribuir para a recuperação das áreas antropizadas na Amazônia.

Nos solos de exploração de petróleo e gás natural em Urucu, estão presentes microrganismos capazes de interagir entre si e influenciar no habitat contribuindo para a recuperação de áreas degradadas. A diversidade microbiana pode ser um importante indicador de qualidade do solo (ZILLI et al., 2003) e do estádio de recuperação de clareiras antropizadas (OLIVEIRA et al., 2019), já que os aspectos ambientais desempenham um importante papel na determinação das interações entre microrganismos e as trocas nas populações de microrganismos no solo. A grande vantagem das raízes micorrízicas em relação as não micorrízicas é que as micorrízicas apresentam duas vias para a absorção dos nutrientes: pela planta e pelos FMA (SMITH et al., 2011; BUCKING et al., 2003).

Neste contexto, as associações plantas- fungos micorrízicos arbusculares se apresentam como uma promissora estratégia para ecossistemas em processo de revegetação, onde as deficiências nutricionais representam uma importante limitação ao desenvolvimento das plantas. Eles podem contribuir na revegetação e crescimento das espécies micorrizadas, pela maior capacidade de absorção de nutrientes, manutenção da diversidade vegetal, melhor capacidade das plantas micorrizadas em competir por nutrientes e água e contribuição para uma eficiente ciclagem de nutrientes e estabilidade do solo (OLIVEIRA et al., 2010b). Os fungos micorrízicos arbusculares são particularmente importantes em regiões tropicais e as micorrizas podem desempenhar um papel crucial para a sobrevivência, crescimento e desenvolvimento das plantas (LEAL et al., 2009; OLIVEIRA et al., 2010a).

Mudas com sistemas radiculares vigorosos e com altas taxas de colonização por fungos micorrízicos arbusculares podem ser de fundamental importância para que possam suportar as situações adversas no primeiro ano após serem introduzidas nas clareiras e jazidas e assim favorecer o crescimento das mesmas.

O objetivo deste estudo foi avaliar as características simbióticas das populações de fungos micorrízicos de solos coletados em áreas de clareiras nas áreas degradadas de Urucu, município de Coari/AM.

\section{METODOLOGIA}

Para avaliar a presença desses fungos nas plantas usadas para a recuperação das jazidas e clareiras de Urucu foram realizadas coletas de solos e raízes de espécies florestais em áreas dentro e nas margens de seis clareiras/jazidas, para as avaliações de fertilidade na profundidade de 0-10 cm (EMBRAPA, 1997). Foram realizadas coletas nas épocas chuvosa (maio) e seca (novembro) no ano de 2010, com cinco repetições para 
Colonizações radiculares por fungos micorrízicos arbusculares (FMAs) em áreas degradadas pela exploração petrolífera no Estado do Amazonas, Brasil

as avaliações de análise química e colonização micorrízica arbuscular das espécies componentes das clareiras/jazidas (Tabela 1 ).

Tabela 1: Dados das clareiras/jazidas de urucu usadas para avaliação da fertilidade e colonização radicular por fungos micorrízicos arbusculares.

\begin{tabular}{cccccl}
\hline CL/JAZ & $\begin{array}{l}\text { Área } \\
\text { (ha) }\end{array}$ & Reflorestada & $\begin{array}{l}\text { No } \\
\text { Esp. }\end{array}$ & Período & Espécies Florestais \\
\hline RUC 40 & 1,8 & dez/98 & 21 & Chuvoso & $\begin{array}{l}\text { Angico, mata-pasto, faveira orelha de macaco, palheteira, abiurana, açaí, } \\
\text { munguba, buriti, pau d'arco, bacaba, embaúba, goiaba de anta, azeitona, } \\
\text { pau de balsa, andiroba, ingá, ingá de macaco, ucuúba, vermelhinho, } \\
\text { visgueiro e mungubarana. }\end{array}$ \\
\hline LUC 22 & 2,3 & jun/01 & 12 & Chuvoso & $\begin{array}{l}\text { Paleteira, angico, faveira, andiroba, angelim, pau d'arco, goiaba de anta, } \\
\text { sucupira, azeitona, embaúba, cumarú e acapurana. }\end{array}$ \\
\hline JAZ 05 & 4,21 & jan/01 & 29 & Chuvoso & $\begin{array}{l}\text { Macucu, munguba, pau de balsa, sorva, mungubarana, ingá, ingá de } \\
\text { macaco, lacre, mata-pasto, açaí, sucupira, buriti, bacaba, angico, angelim } \\
\text { pedra, arapari, acapurana, copaíba, patauá, ucuúba, embaúba, goiaba de } \\
\text { anta, pau d'arco, bacuri, vermelhinho, azeitona, palheteira, visgueiro e fava } \\
\text { orelha-de-macaco. }\end{array}$ \\
\hline $\begin{array}{l}\text { RUC } \\
37 H\end{array}$ & 2,83 & jul/96 & 13 & Seco & $\begin{array}{l}\text { Azeitona, abiurana, cedrorana, ingá, faveira, angico, embaúba, mututi, pau } \\
\text { d'arco, lacre, andiroba, seringa e angelim pedra. }\end{array}$ \\
\hline JAZ 44 & 0,18 & mai/01 & 12 & Seco & $\begin{array}{l}\text { Palheteira, angico, faveira, acapurana, araçá-boi, taxi, angelim pedra, } \\
\text { leucena, ingá, embaúba, goiaba de anta e pau d'arco. }\end{array}$ \\
\hline JAZ-21 & 1,32 & fev/00 & 12 & Seco & $\begin{array}{l}\text { Matapasto, ingá, lacre, goiaba de anta, pau d'arco, sucuúba, mututi, } \\
\text { embaúba, jatobá, andiroba, azeitona e angico. }\end{array}$ \\
\hline
\end{tabular}

As análises químicas foram feitas a partir de amostras de solos secos, destorroados e peneirados (TFSA). Nas análises químicas foram determinados os teores trocáveis de $\mathrm{Ca}, \mathrm{Mg}, \mathrm{K}, \mathrm{Al}, \mathrm{P}$ disponível, $\mathrm{pH}, \mathrm{Fe}$, $\mathrm{Zn}$ e $\mathrm{Mn}$, obedecendo à metodologia descrita pela Embrapa (1997). O pH do solo foi determinado em $\mathrm{H}_{2} \mathrm{O}$ na proporção solo: solução de 1:2,5 e as leituras das amostras foram realizadas no potenciômetro.

A avalição da colonização micorrízica foi feita com lavagem e clarificação (KOH a 10\%), e para quantificar a percentagem de colonização radicular foi utilizada metodologia segundo Kormanik et al. (1980).

\section{RESULTADOS E DISCUSSÃO}

Pelos critérios de Cochrane et al. (1985), considerando o pH e os teores de nutrientes nos solos das clareiras/jazidas estudadas no presente estudo, todos eles são considerados ácidos e de baixa ou média fertilidade (Tabela 2), confirmando a situação de degradação proveniente do processo de retirada da camada superficial para facilitar a perfuração de poços para a extração de petróleo e gás natural.

Tabela 2: Características químicas dos solos amostrados das clareiras cultivadas na Província Petrolífera de Urucu em maio/2010 (chuvoso) e novembro/2010 (seco).

\begin{tabular}{|c|c|c|c|c|c|c|c|c|c|c|}
\hline Época & Local & $\mathrm{pH}\left(\mathrm{H}_{2} \mathrm{O}\right)$ & $\mathrm{Ca}++$ & $\mathrm{Mg++}$ & Al+++ & $\mathrm{K}+$ & $P$ & $\mathrm{Fe}$ & $\mathrm{Zn}$ & $\mathrm{Mn}$ \\
\hline \multicolumn{11}{|c|}{ - } \\
\hline maio/10 & RUC 40 & $4,6 B$ & $3,61 \mathrm{M}$ & $0,26 \mathrm{M}$ & $2,3 \mathrm{~A}$ & $0,18 \mathrm{M}$ & $1,6 \mathrm{~B}$ & $432 \mathrm{~A}$ & 4,15 & $3,2 \mathrm{~B}$ \\
\hline maio/10 & LUC 22 & $4,5 \mathrm{~B}$ & $3,61 \mathrm{M}$ & $0,31 \mathrm{M}$ & $2,1 \mathrm{~A}$ & $0,10 \mathrm{M}$ & $2,9 M$ & $573 A$ & $1,2 \mathrm{~B}$ & $1,5 \mathrm{~B}$ \\
\hline maio/10 & Jazida 5 & $4,5 \mathrm{~B}$ & $0,97 \mathrm{~B}$ & $0,02 \mathrm{~B}$ & $1,2 \mathrm{M}$ & $0,05 \mathrm{~B}$ & $12,7 \mathrm{~A}$ & $123 \mathrm{~A}$ & $0,2 \mathrm{~B}$ & $2,0 \mathrm{~B}$ \\
\hline nov/10 & RUC 37H & $4,8 B$ & $2,96 \mathrm{M}$ & $0,37 \mathrm{M}$ & $1,8 \mathrm{~A}$ & $0,21 \mathrm{M}$ & $3,2 \mathrm{M}$ & $318 \mathrm{~A}$ & $1,9 \mathrm{~B}$ & $1,2 \mathrm{~B}$ \\
\hline nov/10 & Jazida 44 & $3,9 \mathrm{~B}$ & $1,20 \mathrm{M}$ & $0,16 \mathrm{~B}$ & $1,1 \mathrm{M}$ & $0,15 \mathrm{M}$ & $13,1 \mathrm{~A}$ & $323 \mathrm{~A}$ & $0,7 \mathrm{~B}$ & $0,6 \mathrm{~B}$ \\
\hline nov/10 & Jazida 21 & $4,2 B$ & $3,80 \mathrm{M}$ & $0,69 \mathrm{M}$ & $2,2 \mathrm{~A}$ & $0,39 A$ & $675,3 A$ & $240 \mathrm{~A}$ & $30,1 \mathrm{~B}$ & $3,7 \mathrm{~B}$ \\
\hline
\end{tabular}

A classificação dos valores segundo Cochrane et al. (1985): $A$ = alto; $B=$ baixo; $M$ = médio; $S$ = satisfatório.

Os teores de Ca e Mg são considerados médios segundo Cochrane et al. (1985), exceto para a coleta da Jazida 5 no mês de maio, considerado baixo pelos critérios desses autores, sendo bem superiores aos 
encontrados naturalmente nos solos daquela área, conforme documentado por Moreira et al. (2006), sugerindo que nessas clareiras e jazidas houve a aplicação de calcário dolomítico. Como os pHs desses solos estão baixos e os teores de Al altos, pode-se inferir que as doses desse corretivo foram baixas ou então, sua aplicação ocorreu há muito tempo, mantendo-se apenas um efeito residual na forma de teores elevados de Ca e $\mathrm{Mg}$, com o efeito de neutralização da acidez desaparecendo com o tempo entre sua aplicação e a amostragem realizada para o presente estudo.

Os resultados relacionados com a elevada acidez reforçam a afirmação de que a maior parte dos solos da região amazônica é distrófica e de baixa fertilidade (SANCHEZ et al., 1982; MOREIRA et al., 2009) além de elevados teores de Al.

Os teores médios e altos de K e P presentes na maioria dos solos amostrados e, dos teores altos de Fe nos solos, segundo os valores estabelecidos por Cochrane et al. (1985), reforçam a observação de que essas áreas foram também adubadas com esses nutrientes. No entanto, esses adubos não continham quantidades suficientes de $\mathrm{Zn}$ e $\mathrm{Mn}$, devido aos baixos teores encontrados. Ou então, o efeito residual de suas aplicações já desapareceu nos solos. Os baixos teores de $\mathrm{Zn}$ e $\mathrm{Mn}$ em todas as clareiras amostradas também podem ser reflexo da retirada da camada superficial do solo e diminuição drástica da matéria orgânica. Esses dois elementos e o Cu estão geralmente presentes na camada do solo contendo matéria orgânica e como essa camada é retirada para facilitar a perfuração de poços (OLIVEIRA et al., 2010a), era de se esperar que seus teores seriam baixos.

Dentro das clareiras/jazidas, a colonização por fungos micorrízicos arbusculares nas raízes das espécies amostradas no período chuvoso variou entre $0,0 \%$ e $44,4 \%$, com a azeitona apresentando a maior colonização, seguida pelo mata pasto com $40,8 \%$ ambos no RUC 40 e a palheteira não apresentou colonização (Tabela 3). As demais espécies apresentaram baixos níveis de colonização, não ultrapassando 30,0\% de taxa de colonização. Os baixos índices de colonização podem convergir como um indício de que as condições edafoclimáticas e as características genéticas das plantas e fungos não favorecem a simbiose plantas-fungos nas clareiras amostradas.

Tabela 3: Colonização radicular por fungos micorrízicos arbusculares nas espécies cultivada dentro das clareiras na Província de Urucu.

\begin{tabular}{|c|c|c|c|c|c|}
\hline $\begin{array}{l}\text { Clareira/ } \\
\text { Jazida }\end{array}$ & Período & Espécies & Hifas & Vesículas & Col. Total \\
\hline \multirow[t]{6}{*}{ RUC 40} & chuvoso & Azeitona (Sizygium jambolana DC.) & 5,2 & 44,4 & 44,4 \\
\hline & & Angico (Anadenanthera peregrina (L.) Speg.) & 1,6 & 17,6 & 17,6 \\
\hline & & Ingá (Inga edulis) Mart. & 2,4 & 11,2 & 12,4 \\
\hline & & Mata pasto (Senna reticulata) (Willd.) H. S. Irwin ; Barneby & 6,8 & 40,8 & 40,8 \\
\hline & & Pau balsa (Ochroma pyramidale (Cav. ex Lam.) Urban & 2,0 & 16,0 & 16,0 \\
\hline & & Médias da RUC 40 & 3,6 & 26,0 & 26,2 \\
\hline \multirow[t]{6}{*}{ LUC 22} & chuvoso & Andiroba (Carapa guianensis Aublet) & 10,0 & 15,6 & 22,0 \\
\hline & & Visgueiro Parkia pendula (Willd.) Benth. ex Walp. & 1,6 & 6,0 & 6,8 \\
\hline & & Azeitona (Sizygium jambolana DC.) & 0,0 & 22,8 & 22,8 \\
\hline & & Palheteira (Clitoria fairchildiana R. Howard) & 0,0 & 0,0 & 0,0 \\
\hline & & Lacre (Vismia guianensis (Aubl.) Choisy) & 1,7 & 28,6 & 28,6 \\
\hline & & Médias da LUC 22 & 2,7 & 14,6 & 16,0 \\
\hline Jazida 5 & chuvoso & Pau d'arco (Tabebuia serratifolia (vahl) Nich. & 3,6 & 18,8 & 18,8 \\
\hline
\end{tabular}


Colonizações radiculares por fungos micorrízicos arbusculares (FMAs) em áreas degradadas pela exploração petrolífera no Estado do Amazonas, Brasil

MEDEIROS, G. S.; MOREIRA, F. W.; OLIVEIRA, L. A.

\begin{tabular}{|c|c|c|c|c|c|}
\hline & & Angico (Anadenanthera peregrina (L.) Speg.) & 5,8 & 13,8 & 13,8 \\
\hline & & Ingá (Inga edulis) Mart. & 9,2 & 15,2 & 15,2 \\
\hline & & Goiaba de anta (Bellucia grossularioides (L.) Triana & 1,6 & 11,6 & 11,6 \\
\hline & & Palheteira (Clitoria fairchildiana R. Howard) & 0,4 & 22,4 & 22,4 \\
\hline & & Médias da Jazida 5 & 4,1 & 16,4 & 16,4 \\
\hline RUC37H & seco & Azeitona (Sizygium jambolana DC.) & 0,0 & 4,0 & 4,0 \\
\hline & & Goiaba de anta (Bellucia grossularioides (L.) Triana & 5,2 & 9,5 & 9,5 \\
\hline & & Lacre (Vismia guianensis (Aubl.) Choisy) & 3,4 & 4,3 & 4,3 \\
\hline & & Imbaúba (Cecropia peltata) L, C. glaziovi Snethlage & 0,0 & 7,2 & 7,2 \\
\hline & & Mata pasto (Senna reticulata) (Willd.) H. S. Irwin ; Barneby & 1,8 & 20,7 & 20,7 \\
\hline & & Médias da RUC 37H & 2,1 & 9,1 & 9,1 \\
\hline Jazida 44 & seco & Ingá chinelo (inga cinnamomea Spruce ex Benth. & 3,9 & 25,9 & 25,9 \\
\hline & & Angico (Anadenanthera peregrina (L.) Speg.) & 7,1 & 50,7 & 50,7 \\
\hline & & Angelim pedra (Dinizia excelsa Ducke) & 6,8 & 21,6 & 21,6 \\
\hline & & Lacre (Vismia guianensis (Aubl.) Choisy) & 2,8 & 29,6 & 29,6 \\
\hline & & Azeitona (Sizygium jambolana DC.) & 0,4 & 29,6 & 29,6 \\
\hline & & Médias da Jazida 44 & 4,2 & 31,5 & 31,5 \\
\hline Jazida 21 & seco & Angelim pedra (Dinizia excelsa Ducke) & 3,6 & 18,8 & 18,8 \\
\hline & & Angico (Anadenanthera peregrina (L.) Speg.) & 5,8 & 13,8 & 13,8 \\
\hline & & Ingá (Inga edulis) Mart. & 9,2 & 15,2 & 15,2 \\
\hline & & Goiaba de anta (Bellucia grossularioides (L.) Triana & 1,6 & 11,6 & 11,6 \\
\hline & & Lacre (Vismia guianensis (Aubl.) Choisy) & 0,4 & 22,4 & 22,4 \\
\hline & & Médias da Jazida 21 & 4,1 & 16,4 & 16,4 \\
\hline
\end{tabular}

Em contrapartida, a existência de apenas uma espécie com taxa de colonização nula $(0,0 \%)$ confirma a ocorrência generalizada das micorrizas arbusculares em plantas vasculares, reafirmando o caráter cosmopolita dessa simbiose. A associação entre FMA e raízes de plantas está presente na maioria das plantas superiores (COLODETE et al., 2014). As micorrizas arbusculares são o tipo mais comum, ocorrendo em 80 \% das espécies de plantas vasculares e resultam da colonização das raízes por fungos simbióticos obrigatórios (OEHL et al., 2011). Segundo Van der Heijden et al. (1998), as associações micorrízicas devem sempre ser consideradas quando se busca entender a ecologia e a evolução das plantas, suas comunidades e ecossistemas.

Os baixos índices de hifas encontrados sugerem que a simbiose com os fungos pouco ou nada contribuem para a nutrição das plantas, confirmando outros dados encontrados em Urucu em estudos anteriores (MOREIRA et al., 2006). Com relação à taxa de colonização por vesículas, as maiores taxas foram obtidas na coleta do RUC 40, azeitona e mata pasto.

A colonização por fungos micorrízicos arbusculares nas raízes das espécies amostradas no período seco variou entre 4,0 e 50,7\% A maior média de taxa de colonização (31,5\%) das espécies vegetais amostradas dentro da clareira foi encontrada na JAZ 44, apesar da jazida estudada ter apresentado elevado teor de fósforo, o que normalmente diminui a colonização micorrízica (ABBOTT et al., 1991; BRUNDRETT, 1991; SAGGIN JÚNIOR et al., 1994). As menores taxas de colonização ocorreram no RUC 37H, com a azeitona apresentando $4,0 \%$ e o lacre $4,3 \%$.

As demais espécies não ultrapassaram $30,0 \%$ de taxa de colonização. A média geral da taxa de colonização foi considerada baixa para a época, em torno de $20,0 \%$, considerando que o mês de novembro possui níveis menores de pluviosidade em relação ao mês de maio, tornando o período não propício para a 
emissão de novas raízes finas e absorção de água e nutrientes pelas plantas.

Analisando as espécies amostradas por cada clareira/jazida e as estruturas que compõe os fungos, as hifas apresentaram taxas bem inferiores em relação à taxa de colonização por vesículas. Deve-se enfatizar aqui, que as hifas são estruturas fúngicas responsáveis pela exploração radicular pela água e nutrientes do solo, enquanto que as vesículas são as estruturas fúngicas responsáveis pelo armazenamento de nutrientes e energia do fungo. Isso significa que nas associações plantas - fungos vesículo-arbusculares, os fungos estão mais na situação de armazenamento de nutrientes para seu próprio uso do que em contribuírem para uma melhor capacidade das plantas em explorarem a baixa fertilidade e umidade dos solos.

A colonização radicular por hifas não ultrapassou $10 \%$ e as menores taxas ocorreram no RUC $37 \mathrm{H}$, apesar do solo dessa clareira apresentar o menor teor de $\mathrm{P}$, fator determinante para que houvesse a maior colonização de hifas das espécies vegetais, tendo em vista que esse nutriente interfere negativamente na colonização radicular por fungos micorrízicos arbusculares (SMITH et al., 2010; MOREIRA et al., 2019).

A colonização radicular com vesículas variou de 4,0\% a 50,7 e assim como as hifas, as menores taxas foram observadas no RUC 37H e em contrapartida as maiores ocorreram na JAZ 44, uma explicação possível para uma taxa de colonização média de $31,5 \%$, mesmo com uma elevada concentração de $P$ (> $10 \mathrm{mg}$ de $P$ $\mathrm{dm}^{3}$ de solo). Uma explicação para esses resultados seria que não é o $\mathrm{P}$ do solo que regula a colonização micorrízica, mas a quantidade absorvida pela planta (BAGYARAJ, 1992). No entanto, os mecanismos pelo qual o P regula o desenvolvimento da simbiose micorrízica ainda não são conhecidos (KIRIACHEK et al., 2009).

Nas áreas às margens das clareiras/jazidas (Tabela 4), as ocorrências de hifas não ultrapassam 7,0 \% de taxa de colonização no período chuvoso.

Tabela 4: Colonização radicular por fungos micorrízicos arbusculares nas espécies encontradas às margens das clareiras na Província de Urucu.

\begin{tabular}{|c|c|c|c|c|c|}
\hline $\begin{array}{l}\text { Clareira/ } \\
\text { Jazida }\end{array}$ & Período & Espécies & Hifas & Vesículas & Col. Total \\
\hline \multirow[t]{6}{*}{ RUC 40} & chuvoso & Envira (Xylopia bentamii R. E. Fries & 4,0 & 0,0 & 4,0 \\
\hline & & Ucuúba branca (Virola venosa Warb.) & 1,0 & 1,0 & 2,0 \\
\hline & & Araçá (Myrcia graciliflora Sagot.) & 3,0 & 0,0 & 3,0 \\
\hline & & Taxi (Aspidosperma macrocarpon Mart. & 3,0 & 1,0 & 4,0 \\
\hline & & Cacau do mato (Theobroma sylvestre Aubl.) & 2,0 & 0,0 & 2,0 \\
\hline & & Médias da RUC 40 & 2,6 & 0,4 & 3,0 \\
\hline \multirow[t]{6}{*}{ LUC 22} & chuvoso & Cacau (Carapa guianensis Aublet) & 3,0 & 1,0 & 4,0 \\
\hline & & Araçá (Myrcia graciliflora Sagot.) & 6,0 & 0,0 & 6,0 \\
\hline & & Imbaúba (Cecropia concolor Hort. Schoenbr.) & 4,0 & 1,0 & 4,0 \\
\hline & & Abiurana (Lacunaria acreana Ducke) & 2,0 & 0,0 & 2,0 \\
\hline & & Visgueiro (Parkia pendula Benth.) & 4,0 & 1,0 & 5,0 \\
\hline & & Médias da LUC 22 & 3,8 & 0,6 & 4,2 \\
\hline \multirow[t]{6}{*}{ Jazida 5} & chuvoso & Ucuúba (Iryanthera elliptica Ducke) & 3,0 & 1,0 & 4,0 \\
\hline & & Pau mulato (Calycophyllum spruceanum (Benth.) K. Schum. & 6,0 & 1,0 & 7,0 \\
\hline & & Macucu (Licania parviflora) Benth.. & 3,0 & 0,0 & 3,0 \\
\hline & & Bacuri (Rheedia brasiliensis Planch. ; Triana & 2,0 & 1,0 & 3,0 \\
\hline & & Pau roxo (Peltogyne paniculata ssp. paniculata M. F. Silva) & 2,0 & 0,0 & 2,0 \\
\hline & & Médias da Jazida 5 & 3,2 & 0,6 & 3,8 \\
\hline \multirow[t]{3}{*}{ RUC 37H } & seco & Jitó (Guarea carinata Ducke) & 12,0 & 4,0 & 16,0 \\
\hline & & Imbaúba (Cecropia concolor Hort. Schoenbr.) & 5,0 & 6,0 & 11,0 \\
\hline & & Envireira (Iryanthera grandis Ducke) & 5,0 & 12,0 & 17,0 \\
\hline
\end{tabular}


Colonizações radiculares por fungos micorrízicos arbusculares (FMAs) em áreas degradadas pela exploração petrolífera no Estado do Amazonas, Brasil

MEDEIROS, G. S.; MOREIRA, F. W.; OLIVEIRA, L. A.

\begin{tabular}{|c|c|c|c|c|c|}
\hline & & Mata-mata (Eschweilera coriacea Martius) & 6,0 & 3,0 & 9,0 \\
\hline & & Louro preto (Aniba burchelii Kosterm.) & 4,0 & 3,0 & 7,0 \\
\hline & & Médias da RUC 37H & 6,4 & 5,6 & 12,0 \\
\hline \multirow[t]{6}{*}{ Jazida 44} & seco & Breu amarelo (Protium giganteum Engl.). & 5,0 & 0,0 & 5,0 \\
\hline & & Macucu (Couepia guianensis Aubl.) & 5,0 & 0,0 & 5,0 \\
\hline & & Sangue de touro (Iryanthera laevis Markgraf) & 4,0 & 2,0 & 6,0 \\
\hline & & Seringueira (Hevea guianensis Aubl.) & 2,0 & 1,0 & 3,0 \\
\hline & & Mututi (Swartzia discocarpa Ducke ) & 6,0 & 3,0 & 9,0 \\
\hline & & Médias da Jazida 44 & 4,4 & 1,2 & 5,6 \\
\hline \multirow[t]{6}{*}{ Jazida 21} & seco & Virola (Virola cuspidata Warb) & 4,0 & 1,0 & 6,0 \\
\hline & & Ingá guamo (Inga scabriuscula Benth.) & 3,0 & 2,0 & 5,0 \\
\hline & & Sucupira (Bowdichia nitida Spruce) & 5,0 & 2,0 & 7,0 \\
\hline & & Macucu (Couepia guianensis Aubl.) & 4,0 & 5,0 & 9,0 \\
\hline & & Abiurana (Lacunaria acreana Ducke) & 2,0 & 2,0 & 4,0 \\
\hline & & Médias da Jazida 21 & 3,8 & 2,4 & 6,2 \\
\hline
\end{tabular}

O pau mulato apresentou maior taxa de colonização total $(7,0 \%)$ e as menores taxas $(2,0 \%)$ foram observadas na ucuúba branca, cacau do mato, abiurana e pau roxo. Os índices de colonização total radicular por FMA são baixos em todas as espécies coletadas às margens da clareira para esse período, sendo as espécies vegetais estudadas, pouco beneficiadas por esta simbiose. No período seco, a maior colonização por hifas ocorreu no jitó com $12 \%$. As menores colonizações com essas estruturas foram encontradas na seringueira e abiurana, com apenas $2 \%$ de colonização.

As vesículas ocorreram em $0,0 \%$ a $12 \%$ das raízes. Os dados das espécies vegetais coletados às margens das clareiras no mês de novembro apresentaram taxa de colonização micorrízica para hifas, superior em todas as espécies/clareiras amostradas em relação às vesículas. Com exceção da RUC $37 \mathrm{H}$, todas as espécies vegetais amostradas dentro das clareiras (Tabela 3) apresentaram taxas de colonização total micorrízica superior às mesmas espécies amostradas às margens das clareiras (Tabela 4), corroborando com os estudos de que diversos fatores podem afetar a colonização micorrízica em raízes de plantas, estando entre eles: a incidência de luz (GEHRING, 2003), a disponibilidade de água (ENTRY et al., 2002), bem como fatores relacionados com o fungo, a planta e fatores químicos e físicos dos solos (BEDINI et al., 2009).

\section{CONCLUSÕES}

Todos os solos mostraram-se ácidos e com teores elevados de Alumínio, com a maioria indicando a aplicação de adubação, principalmente com Ca, Mg, K, P e Fe. Os baixos índices de hifas encontrados sugerem que a simbiose com os fungos pouco ou nada contribuíram para a nutrição das plantas.

AGRADECIMENTOS: À CAPES pela concessão de bolsa ao primeiro autor durante o mestrado em Agricultura no Trópico Úmido (INPA); e, FINEP e PETROBRAS pelo apoio financeiro que viabilizou o estudo.

\section{REFERÊNCIAS}

ABBOTT, L. K.; ROBSON, A. D.. Factors influencing the occurrence of vesicular arbuscular mycorrizas. Agriculture, Ecosystems and Environment, v.35, n.2-3, p.121-150, 1991. DOI: http://doi.org/10.1016/0167-8809(91)90048-3
BAGYARAJ, J.. Ecology of vesicular: arbuscular mycorrhizae. In: ARORA, D. K.; RAI, B.; MUCKERJI, K. G.; KNUDSEN, G. R.; DEKKER, M.. Handbook of Applied Mycology. Journal of Environmental Quality, v.21, n.4, p.740-741, 1992. DOI: https://doi.org/10.2134/jeq1992.00472425002100040035x 
BEDINI, S.; PELLEGRINO, E.; AVIO, L.; PELLEGRINI, S.; BAZZOFFI, P.; ARGESE, E.; GIOVANNETTI, M.. Changes in soil aggregation and glomalin-related soil protein content as affected by the arbuscular mycorrhizal fungal species Glomus mosseae and Glomus intraradices. Soil Biol. Biochem, v.41, n.7, p.1491-1496, 2009. DOI: https://doi.org/10.1016/i.soilbio.2009.04.005

BRUNDRETT, M.. Mycorrhizas in natural ecosystems. Advances in Ecological Research, v.21, p.171313, 1991.

BUCKING, H.; HEYSER, W.. Uptake and transfer of nutrients in ectomycorrhizal associations: interactions between photosynthesis and phosphate nutrition. Mycorrhiza, v.13, p.59-68, 2003. DOI: http://doi.org/10.1007/s00572-002$\underline{0196-3}$

COCHRANE, T. T.; SÁNCHEZ, L. G.; AZEVEDO, L. G.; PORRAS, J. A.; GARVER, C. L.. Land in Tropical América. A teoria na América Tropical. Planaltina: Centro Internacional de Agricultura Tropical (CIAT), Cali. Colômbia (EMBRAPA-CPCA). 1985.

COLODETE, C. M.; DOBBSS L. B.; RAMOS, A. C.. Aplicação das Micorrizas arbusculares na recuperação de áreas impactadas. Natureza, v.12, n.1, p.31-37, 2014.

EMBRAPA. Centro Nacional de Pesquisa de Solos. Manual de métodos de análise de solos. 2 ed. Rio de Janeiro: EMBRAPA, 1997.

ENTRY, J. A.; RYGIEWIEZ, P. T.; WATRUD, L. S.; DONNELLY, P. $K$.. Influence of adverse soil conditions on the formation and function of arbuscular mycorrhizas. Advances in Environmental Research, v.7, p.123-138, 2002.

GEHRING, C. A.. Growth responses to arbuscular mycorrhizae by rain forest seedlings vary with light intensity and tree species. Plant Ecology, v.167, p.127-139, 2003. DOI: http://doi.org/10.1023/A:1023989610773

KIRIACHEK, S. G.; AZEVEDO, L. C. B.; PERES, L. E. P.; LAMBAIS, M. R.. Regulação do desenvolvimento de micorrizas arbusculares. Revista Brasileira de Ciência do Solo, v.33, p.1-16, 2009. DOI: https://doi.org/10.1590/S0100-06832009000100001

KORMANIK, P. P.; BRYAN, W. C.; SCHULTZ, R. C.. Procedures and equipment for staining large number of plant roots for endomycorrhizal assay. Canadian Journal of Microbiology, v.26, p.536-538, 1980.

LEAL, P. L.; STÜRMER, S. L.; SIQUEIRA, J. O.. Occurrence and diversity of arbuscular mycorrhizal fungi in trap cultures from soils under different land use systems in the Amazon. Brazil. Braz. J. Microbiol, v.40, n.1, p.111-121, 2009. DOI: http://doi.org/10.1590/S1517-838220090001000019

MOREIRA, A.; MORAES, L. A. C.; FAGEIRA, N. K.. Potential of rubber plantations for environmental conservation in Amazon Region. Bioremediation, Biodiversity and Bioavailability, v.3, n.1, p.1-5, 2009.
MOREIRA, F. M. S.; SIQUEIRA, J. O.. Microbiologia e

Bioquímica do Solo. Lavras: UFLA, 2006.

MOREIRA, S. D.; FRANÇA, A. C.; GRAZZIOTTI, P. H.; LEAL, F. D. S.; SILVA, E. B.. Arbuscular mycorrhizal fungi and phosphorus doses on coffee growth under a non-sterile soil. Rev. Caatinga, v.32, n.1, p.72-80, 2019. DOI: https://doi.org/10.1590/1983-21252019v32n108rc

OEHL, F.; SIEVERDING, E.; PALENZUELA, J.; INEICHEN, K.; SILVA, G. A.. Advances in Glomeromycota taxonomy and classification. IMA Fungus, v.2, p.191-199, 2011. DOI: http://doi.org/10.5598/imafungus.2011.02.02.10

OLIVEIRA, L. A.; MOREIRA, F. W.. Colonização das raízes de plantas da Amazônia por fungos micorrízicos arbusculares. In: Conhecimento, conservação e uso de fungos. Manaus: INPA, 2019. p.53-59.

OLIVEIRA, A. N.; OLIVEIRA, L. A.. Micorrizas arbusculares no bioma Amazônia In: Micorrizas: 30 anos de pesquisas no Brasil. Lavras: UFLA, 2010b. p.251-277.

OLIVEIRA, L. A.; SAID, M. M.; SILVA, J. M..

Recuperação/Restauração de áreas alteradas/degradadas na Amazônia Brasileira. In: Tecnologias para a recuperação de ecossistemas e conservação da biodiversidade na Amazônia brasileira: III Reunião Científica da Rede CTPetro Amazônia. Manaus: INPA, 2010a. p.1-5.

SAGGIN JUNIOR, O. J.; SIQUEIRA, J. O.; GUIMARÃES, P. T. G.; OLIVEIRA, E.. Interação fungos micorrízicos versus superfosfato e seus efeitos no crescimento e teores de nutrientes do cafeeiro em solo não fumigado. Revista Brasileira de Ciência do Solo, v.18, p.27-36, 1994.

SANCHEZ, P. A.; BANDY, D. E.; VILLACHICA, J. H.; NICHOLAIDES, J. J.. Amazon basin soils: management for continuous crop production. Science, v.216, p.821-827, 1982.

SMITH, S. E.; FACELLI, E.; POPE, S.; SMITH, F. A.. Plant performance in stressful environments: interpreting new and established knowledge of the roles of arbuscular mycorrhizas. Plant and Soil, v.326, p.3-20, 2010. DOI: http://doi.org/10.1007/s11104-009-9981-5

SMITH, S. E.; SMITH, F. A.. Roles of arbuscular mycorrhizas in plant nutrition and growth: new paradigms from cellular to ecosystem scales. Annual Review of Plant Biology, v.62, p.227-250, 2011. https://doi.org/10.1146/annurev-arplant042110-103846

VAN DER HEIJDEN, M. G. A.;

BOLLER, T.; WIEMKEN, A.; SANDERS, I. R.. Different arbuscular mycorrhizal fungal species are potential determinants of plant community structure. Ecology, v.79, p.2082-2091, 1998.

ZILLI, J. E.; RUMJANEK, N. G.; XAVIER, G. R.; COUTINHO, H. L. C.; NEVES, M. C. P. N.. Diversidade microbiana como indicador da qualidade do solo. Cad. Ciência e Tecnologia, v.20, p.391-411, 2003

A CBPC - Companhia Brasileira de Produção Científica (CNPJ: 11.221.422/0001-03) detém os direitos materiais desta publicação. Os direitos referem-se à publicação do trabalho em qualquer parte do mundo, incluindo os direitos às renovações, expansões e disseminações da contribuição, bem como outros direitos subsidiários. Todos os trabalhos publicados eletronicamente poderão posteriormente ser publicados em coletâneas impressas sob coordenação da Sustenere Publishing da Companhia Brasileira de Produção Científica e seus parceiros autorizados. Os (as) autores (as) preservam os direitos autorais, mas não têm permissão para a publicação da contribuição em outro meio, impresso ou digital, em português ou em tradução. 